\title{
Effects of Pre and Probiotic on Growth Performance and Haematological Parameters in Pigs
}

\author{
Andrei- Radu SZAKACS*, Sorana MATEI, Laura ȘTEFĂNUȚ, Zoltan MONI, Adrian MACRI \\ University of Agricultural Science and Veterinary Medicine, Faculty of Veterinary Medicine, Calea \\ Mănăștur, nr.3-5, 400372 Cluj-Napoca, Romania, \\ *corresponding author: andreiradu2004@yahoo.com \\ Bulletin UASVM Veterinary Medicine 73(2) / 2016, \\ Print ISSN 1843-5270; Electronic ISSN 1843-5378 \\ DOI:10.15835/buasvmcn-vm: 12166
}

\begin{abstract}
The present study investigates the effects of dietary supplementation with feed supplements (prebiotics and probiotics) on pig performance, the feed conversion ratio and some haematological parameters.

The research was conducted on hybrid pigs [(Yorkshire $\times$ Landrace) $\times$ Duroc] in a farm from Sălaj County, Romania. Pigs of 11 weeks age $(n=200)$ were divided into 4 equal groups: a group fed with the probiotic, a prebiotic-fed group, a control group and a synbiotic (pre- and probiotic) treated group. The control group was fed without the specified additives. Probiotic treated group was fed with the same feedstuff but containing the additive BetaPlus ${ }^{\circledR}$ Ultra (Biochem) (5.12x1012 CFU/kg -Bacillus subtilis DSM 5750, 5.12x1012UFC/kg -Bacillus licheniformis (DSM 5749) and $921 \mathrm{~g}$ of betaine), in an amount of $1 \mathrm{~kg} /$ tons of feed. Prebiotic group had added to the feed an extract derived from the cell wall of Saccharomyces cerevisiae (TechnoMos® - Biochem) in a dose of 250 $\mathrm{g} /$ ton of feed. The weight of 25 pigs in each compartment was recorded 9 times (over 85 days). Animal health was evaluated via clinical, hematological and parasitological examinations. In day 11 and day 77 and faeces samples were taken from each investigated group. Growth rate, feed consumption and some haematological parameters were measured.

The body weight, average total weight gain and feed conversion rate increase by the dietary inclusion of the both pre- and probiotic. In the compartment treated with prebiotic, the weight of pigs has increased with $1030 \mathrm{~g} /$ day compared to $982 \mathrm{~g} /$ day value recorded in the control group. The average feed consumption was $3.21 \mathrm{~kg} / \mathrm{day}$ in the control group while the group treated with prebiotic was only $2.99 \mathrm{~kg} /$ day. Feed conversion rate for all treated groups were lower than the control one. Haematological parameters varied in physiological limits of species.

These products show promising effects as an alternative for antibiotics in order to eliminate the use of these drugs as growth-promoting additives.
\end{abstract}

Keywords: growth, performance, pigs, prebiotics, probiotics.

\section{INTRODUCTION}

The efficacy of antibiotics as growth promoters in pigs is well documented in numerous studies (Awad et al., 2008; Chen et al., 2005; Chu et al., 2011). Because of the increasing concern regarding implication of antibiotics in development of resistant bacteria (Philips, 1999), alternative methods to improve health and efficiency of growth in pigs are widely investigated
(Awad et al, 2009). Researches showed mostly a limited efficiency on growth improvement of pre- and probiotics (Chen, 2005; Chu et al., 2011; Cromwell, 1991). The lack in alternatives to natural growth stimulants makes further studies of probiotics and prebiotics importance. Health of animals is correlated with a specific intestinal microflora, which in turn is affected in many situations like diseases, feeds, treatments 
or stress (Gibson and Fuller, 2000). In order to maintain a healthy microflora one can use specific additives (pro- and prebiotics). Probiotics were described as "live microorganisms which, when consumed in adequate amounts, confer a health benefit on the host" (Donohue, 2006; FAO, 2002; Guarner and Schaafsma, 1998). The definition of prebiotics presents them as "food ingredients that beneficially affect the host by selectively stimulating the growth and/or the activity of one or a limited number of bacterial species already resident in the colon, and thus attempt to improve host health" (De Vrese and Schrezenmeir, 2001; Gibson and Roberfroid, 1995). A combination of these two additives is called synbiotic. The complex implications of these feed additives on intestinal flora and on immune system were documented by Gourbeyre (2011).

The aim of the study was to measure the effect of feed supplements (pre- and probiotics) on pig growth and on some haematological parameters.

\section{MATERIALS AND METHODS}

\section{Treatments}

The probiotic used was a commercial product (BetaPlus® Ultra - Biochem), which contained live bacterial cultures: 5.12x1012 CFU/kg Bacillus subtilis (DSM 5750), 5.12x1012UFC/kg Bacillus licheniformis (DSM 5749) and $921 \mathrm{~g}$ of betaine. The prebiotic used was TechnoMos® (Biochem) which is an extract of yeast wall (Saccharomyces cerevisiae) containing large quantities of $\beta$-glucans and oligosaccharides.

The prebiotic has important effects on the gastrointestinal system: it controls the gastric $\mathrm{pH}$, it regulates the gut motility and stimulates the non-specific immunity. It also regulates the intestinal microorganism flora by stimulating the growth of normally present bacteria. Synbiotic is obtained by combining pro- and prebiotics and has a stimulating effect on the live bacteria from probiotics together with the local ones.

\section{Animals and protocol}

Pigs (hybrid [(Yorkshire $\times$ Landrace $) \times$ Duroc] $)$ of 11 weeks $(n=200)$ were divided into 4 equal groups: a group fed with the probiotic (PROB), a prebiotic-fed group (PREB), a control group (C) and a symbiotic (pre- and probiotic) treated group (SYNB). The control group was fed with a feed without the specified additives. Probiotic treated group was fed the same feedstuff but containing the additive Beta Plus ${ }^{\circledR}$ Ultra (Biochem) in an amount of $1 \mathrm{~kg} /$ tone of feed. Prebiotic group had added to the feed TechnoMos® (Biochem) in a dose of $250 \mathrm{~g} /$ tone of feed. SYN group received in feed a mixture of both additives with the same dose. Animals were separated in groups of 50 pigs in controlled environment with ad libitum access to water and food. Administration of products, body weight and food intake (quantity of food) were monitored for 85 days. Pigs were fed with a starter fodder from day 0 to day 21; growing fodder was given from day 22 to day 56 and from day 57 to day 85 was considered a finishing period. In days 11 and 77 samples were collected for haematological and parasitological examinations. During the study, animals were observed for health changes and the absence of parasites was certified by parasitological examination of faeces (Willis method).

\section{Haematological analysis}

For haematological investigation, blood was collected (with EDTA) from the auricular vein. Haematological analyses were the following: haematocrit, haemoglobin, determination of total number of erythrocytes and leucocytes (tab.1). Determinations were performed by automated methods with Abacus Junior Vet haematology analyser.

\section{Growth performance}

25 animals (randomly selected) from each group were weighted 9 times during the study. Weight gain for each dietary treatment was calculated and for each period (total body weight gain TBWG = weight at day 85 - weight at day 0 ). Feed consumption was recorded during the whole study for each treatment and the feed conversion rate (FCR) was calculated subsequently.

\section{Statistical analysis}

Statistical analyses were conducted with the GraphPad InStat to determine if variables differed between groups. The Kolmogorov-Smirnov test was used to test the normal distribution of the data before statistical analysis was performed. Results are expressed as means \pm SD. All the investigated parameters were compared between groups by one-way ANOVA and subsequent Welch test. Probability values of less than $0.05(\mathrm{P}<0.05)$ were 
considered significant and over 0.05 insignificant $(\mathrm{P}>0.05)$.

\section{RESULTS AND DISSCUSION}

Haematological analysis

We have not observed significant changes of haematological parameters and the variations were between the physiological limits depending on species and age. No significant differences were observed compared to control group.

The haematocrit presented values between $36.74 \pm 1.73 \%$ (PROB-group) - $40.25 \pm 1.69 \%$ (SYNB-group) for day 11 and $37.86 \pm 1.09 \%$ (PROB-group) - 40.12 $\pm 0.98 \%$ (PREB-group) for day 77. According to these values is the evolution of RBC levels, the values being relatively constant in all groups for both determinations $(5.99 \pm 0.60$ $7.04 \pm 0.52 \mathrm{~T} / \mathrm{L}$ ). (Tab. 2).

We monitored the level of total number of leucocytes. The most important difference was observed in case of administration of probiotic (PROB-group), which produced an important increase $(\mathrm{P}<0.05)$ of total leukocytes; the level of this parameter was $14.37 \pm 1.27 \mathrm{G} / \mathrm{L}$ for first determination, and $20.24 \pm 1.08 \mathrm{G} / \mathrm{L}$ for the end of the study. Also, the increasing of total leukocytes was important for PREB-group (13.25 $\pm 1.97 \mathrm{G} / \mathrm{L}-17.92 \pm 1.11 \mathrm{G} / \mathrm{L}$ ) (tab. 2). Generally, the administration of probiotics induce the immunostimulation by different mechanisms, one of the most important is the production of cytokines, which are involved in the control of leucopoiesis.

\section{Growth performance}

The weight gain of studied animals in the starter period was $25.5 \mathrm{~kg}$ for control group (tab.3), with a fodder consumption of $2074.5 \mathrm{~kg}$ (tab. 4). In the growing period, the highest weight gain (38.3 $\mathrm{kg}$ ) was measured for the PROB group with a feed consumption of $5318.5 \mathrm{~kg}$. The finishing period shows different evolution of the weight gain, PREB group having the highest value $(31.8 \mathrm{~kg})$ but the lowest feed consumption being recorded in PROB group (4333 kg).

The PROB group had a limited weight gain for the finishing period to only $26.1 \mathrm{~kg}$. The results obtained for the whole study shows that best weight evolution have been registered in the prebiotic treated group (87.6 kg) and the lowest feed consumption had the PROB group (tab. 3, tab. 4). These aspects are underlined by the evolution

Tab. 1. The methods used for haematological investigation

\begin{tabular}{ccccc}
\hline No. & $\begin{array}{c}\text { INVESTIGATED } \\
\text { PARAMETERS }\end{array}$ & METHOD & UNIT OF MEASUREMENT & REFERENCES* \\
\hline $\mathbf{1 .}$ & Haematocrit (PVC) & $\begin{array}{c}\text { Calculation - the number } \\
\text { of red blood cells }\end{array}$ & $\%$ & $36-43$ \\
\hline $\mathbf{2 .}$ & Haemoglobin (Hgb) & Cyanmethaemoglobin method & $\mathrm{g} / \mathrm{dl}$ & $9-13$ \\
\hline $\mathbf{3 .}$ & $\begin{array}{c}\text { Total number of } \\
\text { erythrocytes (RBC) }\end{array}$ & Impedance method & $\mathrm{T} / \mathrm{L}$ & $5-7$ \\
\hline $\mathbf{4 .}$ & $\begin{array}{c}\text { Total number of } \\
\text { leucocytes (WBC) }\end{array}$ & Impedance method & $\mathrm{G} / \mathrm{L}$ & $11-22$ \\
\hline Merck Veterinary Manual (2014) & &
\end{tabular}

Tab. 2. Haematological investigated parameters (average \pm SD) of the experimental group

\begin{tabular}{ccccccccc}
\hline GROUPS & \multicolumn{7}{c}{ PARAMETERS } \\
\cline { 2 - 9 } & \multicolumn{2}{c}{ PVC (\%) } & \multicolumn{2}{c}{ Hgb (g/dl) } & \multicolumn{2}{c}{ RBC (T/L) } & \multicolumn{2}{c}{ WBC (G/L) } \\
\cline { 2 - 9 } & Day 11 & Day 77 & Day 11 & Day 77 & Day 11 & Day 77 & Day 11 & Day 77 \\
\hline PROB & $36.74 \pm 1.73$ & $37.86 \pm 1.09$ & $11.32 \pm 0.92$ & $11.98 \pm 1.11$ & $6.83 \pm 0.41$ & $5.99 \pm 0.60$ & $14.37 \pm 1.27$ & $20.24 \pm 1.08^{*}$ \\
\hline PREB & $37.05 \pm 2.83$ & $40.12 \pm 0.98$ & $11.10 \pm 0.88$ & $11.23 \pm 0.10$ & $6.46 \pm 0.50$ & $6.77 \pm 0.42$ & $13.25 \pm 1.97$ & $17.92 \pm 1.11^{*}$ \\
\hline SYNB & $40.25 \pm 1.69$ & $39.76 \pm 2.32$ & $10.72 \pm 0.35$ & $12.04 \pm 0.60$ & $7.01 \pm 0.66$ & $6.06 \pm 0.23$ & $19.62 \pm 2.82$ & $19.96 \pm 1.45$ \\
\hline C & $37.10 \pm 1.02$ & $38.82 \pm 1.43$ & $11.00 \pm 1.30$ & $10.84 \pm 0.87$ & $7.04 \pm 0.52$ & $6.66 \pm 0.34$ & $17.74 \pm 3.01$ & $18.54 \pm 1.22$ \\
\hline PROB=probiotic; PREB=prebiotic; SYNB=synbiotic; C=control; *=significant difference & 7 & & &
\end{tabular}


of feed conversion ratio (FCR) (tab. 5), which indicate a good value for the probiotic treated group while control had a FCR of 3.172 .

The group treated with synbiotic presented an overall good weight gain $(86.3 \mathrm{~kg})$ but with a relative high feed consumption $(11,762.0 \mathrm{~kg})$ and a feed conversion ratio of 2.896 .

The comparative analyses of the data indicates that highest weight gain was measured in the prebiotic treated group but the lowest feed consumption was of the probiotic treated group, and this is why the best FCR was calculated for the PROB group. The recorded differences between the four investigated groups for all growth parameters are not statistically assured.

The impact of prebiotic, probiotic and synbiotic products on the health and growth performance of animals is based on their capacity to alter the bacterial structure on the intestine stimulating the normally present bacteria and not the pathogenic microorganisms. This additives impact directly on the immune system present in the digestive tract (De Vrese and Schrezenmeir, 2008).
Similar results were obtained in a study per formed on mice by Stefănut (2015) where the lowest feed conversion rate (FCR) was measured for probiotic treated group and all other groups presenting higher values. In an investigation of the performance impact of similar additives on broiler chickens it was concluded that the growth parameters were improved by the dietary inclusion of the both pre- and probiotic compared with the control group (Szakacs et al., 2015).

Feed products that are classified as probiotics, prebiotics and competitive exclusion cultures have been utilized as pathogen reduction strategies in animal food with varying degrees of success. The efficacy of these products is often due to specific microbial ecological factors, which alter the competitive pressures experienced by microbial population of the gut (Callaway et al., 2008).

The probiotics and prebiotics have different properties regarding pig health and growth. Probiotics impact on pathological microorganisms growth, by producing substances like bacteriocins (antibiotics) or acids like acetic and propionic (Cotter et al., 2005). Because of their

Tab.3. Average growth rate of the pigs in the studied groups (kg/stage)

\begin{tabular}{ccccc}
\hline Period $\backslash$ Treatment & PREB & PROB & SYNB & C \\
\hline Starter & 21.5 & 20.5 & 23.5 & 25.5 \\
\hline Growing & 34.3 & 38.3 & 35.7 & 36.6 \\
\hline Finishing & 31.8 & 26.1 & 27.1 & 21.4 \\
\hline TOTAL & 87.6 & 84.9 & 86.3 & 83.5 \\
\hline
\end{tabular}

Tab.4. Total feed consumption for each growing period and for the total time period (kg)

\begin{tabular}{ccccc}
\hline Period $\backslash$ Treatment & PREB & PROB & SYNB & C \\
\hline Starter & 1733.5 & 1635 & 1843.5 & 2074.5 \\
\hline Growing & 5127.5 & 5318.5 & 5435 & 5473 \\
\hline Finishing & 4466 & 4333 & 4486 & 4649.5 \\
\hline TOTAL & $11,327.00$ & $11,286.50$ & $11,762.50$ & $12,197.00$ \\
\hline
\end{tabular}

Tab.5. Feed conversion rate calculated for each growing stage and for the total period

\begin{tabular}{ccccc}
\hline Period $\backslash$ Treatment & PREB & PROB & SYNB & C \\
\hline Starter & 1.790 & 1.692 & 1.659 & 1.764 \\
\hline Growing & 3.320 & 2.953 & 3.238 & 3.248 \\
\hline Finishing & 3.119 & 3.528 & 3.520 & 4.719 \\
\hline TOTAL & 2.872 & 2.825 & 2.896 & 3.172 \\
\hline
\end{tabular}


capacity to adhere to the epithelial cells of the gastrointestinal tract probiotic bacteria reduce the pathogens and toxins by enhancing the intestinal barrier (Gourbeyre et al., 2011). A number of 12 strains of Bifidobacteria were analysed in order to determine which has a higher impact on growth performance of weaning piglets. The results highlighted that B. animalis subsp. lactis $R a 18$, at $10^{11} \mathrm{CFU}$ per pig per day, appeared to be the best probiotic choice for improved growth performance (Modesto et al., 2009).

Prebiotics ferment ingredients in a selective way, which impact on the composition of intestinal flora. The exact mechanism is not clear yet, but is considered to be related to the production of small chain fatty acid (Scaldaferri et al., 2013).

A combination of probiotic(s) and prebiotic(s) also called synbiotics (Gibson and Roberfroid, 1995; Gourbeyre et al., 2011), it is considered to help the passage of probiotics through digestive tract, and potentates their effect (Zimmerman et al., 2001).

The results of Chu et al. (2011) study suggest that synbiotics have similar effects with antibiotics on the nutrient digestibility and faecal microflora composition in growing pigs. In this study the growth performance of pigs was not affected by supplementation with synbiotics but digestibility of crude protein and dry matter were higher.

Gourbeyre et al. (2011) observed that prebiotics, prebiotics or synbiotics can influence the intestinal microflora and modulate the immune response. This substances influence the innate and adaptive immune responses. This action is caused by stimulation of the cytotoxic activity of NK cells and macrophage phagocytosis.

The general impact of prebiotics and probiotics on pig health is due to the maintenance of a normal ecology on the gastrointestinal tract and the improved digestion and increased feed intake (Awad et al., 2009).

\section{CONCLUSIONS}

The analysis of the results reveals that the administration of pro-, pre- and synbiotic did not have negative effect on the health of animals. The investigated parameters have shown different aspects depending on the experimental group:

1. The treated group with probiotic presented the lowest feed conversion rate because of the reduced total consumed fodder.
2. The treated group with prebiotics had the best evolution regarding weight gain, but with a superior FCR than the group treated with probiotics.

3. All the treated groups presented better results compared with the control group regarding the investigated growth parameters.

4. The probiotic and prebiotic determined stimulation of the immune system by increasing of the total number of leukocytes.

\section{REFERENCES}

1. Awad WA, Chareeb K, Abdel-Raheem S, Bohm J (2009). Effects of dietary inclusion of probiotic and symbiotic on growth performance, organ weight and intestinal histomorphology of broiler chickens. Poult Sci. 2009; 88:49-56

2. Callaway T. R., Edrington T. S., Anderson R. C., Harvey R. B., Genovese K. J., Kennedy C. N. (2008). Probiotics, prebiotics and competitive exclusion for prophylaxis against bacterial disease.Anim Health Res Rev. 9(2):217225.

3. Chen, Y.J., K.S. Son, B.J. Min, J.H. Cho, O.S. Kwon and I.H. Kim (2005b). Effects of dietary probiotic on growth performance, nutrients digestibility, blood characteristics and faecal noxious gas content in growing pigs. AsianAust. J. Anim. Sci. 18(10):1464-1468.

4. Chu Gyo Moon, LEE Shin Ja, JEONG Ho Sik, Sung Sill L (2011). Efficacy of probiotics from anaerobic microflora with prebiotics on growth performance and noxious gas emission in growing pigs Animal Science Journal Vol. 82(2):282-290.

5. Cotter PD, Hill C, Ross RP (2005). Bacteriocins: developing innate immunity for food. Nat Rev Microbiol 3:777-788.

6. Cromwell GL, Stahly TS, Dawson KA, Monegue JJ, Newman K (1991). Probiotics and antibacterial agents for weanling pigs, J.Anim. Sci (Suppl.1):114.

7. De Vrese M, Schrezenmeir J (2001). Probiotics, prebiotics, and synbiotics-approaching a definition. Am J Clin Nutr 73:361S-364S.

8. De Vrese M, Schrezenmeir J (2008). Probiotics, prebiotics, and synbiotics. Adv Biochem Eng Biotechnol 111:1-66.

9. Donohue Diana (2006). Safety of probiotics. Asia Pac J Clin.Nutr. 2006 15(4):563-569.

10. Gibson GR, Fuller R (2000). Aspects of In Vitro and In Vivo Research Approaches Directed Toward Identifying Probiotics and Prebiotics for Human Use. Supplement to The Journal of Nutrition, 391S-395S.

11. Gibson GR, Roberfroi MB (1995). Dietary modulation the human colonic microbiota: introducing the concept of prebiotics. J Nutr 125:1401-1412.

12. Gourbeyre P, Denery S, Bodinier M (2011.) Probiotics, prebiotics, and symbiotics: impact on the gut immune system and allergic reactions. Journal of Leukocyte Biology 89:685-695. 
13. Guarner F, Schaafsma G J (1998). Probiotics. Int J Food Microbiol 39:237-238.

14. Modesto Monica, D’Aimmoa Rosaria, Stefaninia Ilaria, Trevisib P, De Filippib Sara, Casinib Luisa, Mazzonib M. Bosib P, Biavatia B (2009). A novel strategy to select Bifidobacterium strains and prebiotics as natural growth promoters in newly weaned pigs. Livestock Science. Vol. 122(2-3): 248-258.

15. Philips, I (1999). Assessing the evidence that antibiotics growth promoters influence human infections. J. Hospital Infections, 43: 173-178.

16. Scaldaferri F, Gerardi V, Lopetuso LR, Del Zompo F (2013). Gut Microbial Flora, Prebiotics, and Probiotics in IBD:Their Current Usage and Utility. BioMed Research International 2013:1-9.

17. Ştefănuţ Laura Cristina, Mitrea Laura, Ognean L (2015). Effects of Probiotics, Prebiotics and Synbiotics on Some Hematological and Microbiological Parameters in
Laboratory Mice. Bulletin UASVM Veterinary Medicine 72(2): 301-305.

18. Szakacs A.R., Sorana Matei, Laura Stefănut, Reka Simcsak, Macri A (2015). The Impact of Pre and Probiotic on Growing Performance in Ross 708 Broiler Chickens. Bulletin UASVM Veterinary Medicine 72(2):330-335.

19. Zimmermann B, Bauer E, Mosenthin R (2001). Pro- and prebiotics in pig nutrition - potential modulators of gut health? Journal of Animal and Feed Sciences Vol: 10(1):4756.

20. Merck Veterinary Manual (2014).

21. ***FAO/WHO (2002). Guidelines for the evaluation of probiotics in food. Report of a Joint FAO/WHO Working Gup on Drafting Guidelines for the Evaluation of Probiotics in Food. London, Ontario, Canada. FAO/WHO. 